\title{
Manavgat Nehri Nehirağzı Bölgesi Zooplanktonunun Sistematik ve Ekolojik Yönden
} Incelenmesi

\section{Ömer ERDOĞAN*, Ömer Osman ERTAN}

${ }^{1}$ Süleyman Demirel Üniversitesi, Eğirdir Su Ürünleri Fakültesi, Su Ürünleri Temel Bilimler Bölümü / ISPARTA

*Sorumlu yazar:omererdogan@sdu.edu.tr

\section{Özet}

Ocak-Aralık 2009 tarihleri arasında Manavgat Nehri'nden seçilen 5 istasyondan aylık örneklemeler yapılmış, bazı fizikokimyasal değişkenler ile zooplankton tür bileşimi ve yoğunluğu araştırılmıştır.

Manavgat Nehri nehirağzı bölgesinde Copepoda yoğunluğu en yüksek ağustos $\left(22883 \pm 8156 \mathrm{org} / \mathrm{m}^{3}\right)$, en düşük mart $\left(2160 \pm 726 \mathrm{org} / \mathrm{m}^{3}\right)$; Rotifera yoğunluğu en yüksek şubat $\left(1820 \pm 641 \mathrm{org} / \mathrm{m}^{3}\right)$, en düşük eylül $\left(644 \pm 298 \mathrm{org} / \mathrm{m}^{3}\right)$; Cladocera yoğunluğu en yüksek ağustos $\left(2279 \pm 386 \mathrm{org} / \mathrm{m}^{3}\right)$, en düşük ocak $(204 \pm 71$ $\left.\mathrm{org} / \mathrm{m}^{3}\right)$; diğer organizmaların yoğunluğu en yüksek şubat $\left(2105 \pm 530 \mathrm{org} / \mathrm{m}^{3}\right)$, en düşük nisan $(549,49 \pm 202$ org $/ \mathrm{m}^{3}$ ) aylarında belirlenmiştir. Manavgat Nehri nehirağzı bölgesinde baskın olarak görülen türler Oithona nana, Clausocalanus arcuicornis, Acartia discaudata, Paracalanus parvus, Bosmina longirostris ve Keretella cochleris olarak saptanmıştır ve bu türler örihalin karakterindeki zooplankton türleridir.

Anahtar kelimeler: Manavgat Nehri, Östarin, Zooplankton

*Bu çalışma Doktora tezinden özetlenmiştir.

The investigated as taxonomical and ecological of zooplankton in Manavgat Estuary

\begin{abstract}
The physicochemical features and species composition and density of zooplankton of Manavgat estuary investigated monthly sampling from selected 5 stations between January and December, 2009.

In Manavgat River estuarin zone, the highest and the lowest Copepoda density respectively august $\left(22883 \pm 8156\right.$ ind. $\left./ \mathrm{m}^{3}\right)$ and march $\left(2160 \pm 726\right.$ ind. $\left./ \mathrm{m}^{3}\right)$; the highest and the lowest Rotifera density respectively february $\left(1820 \pm 641\right.$ ind. $\left./ \mathrm{m}^{3}\right)$ and september $\left(644 \pm 298\right.$ ind. $\left./ \mathrm{m}^{3}\right)$; the highest and the lowest Cladocera density respectively august $\left(2279 \pm 386\right.$ ind. $\left./ \mathrm{m}^{3}\right)$ and january $\left(204 \pm 71\right.$ ind. $\left./ \mathrm{m}^{3}\right)$; the highest and the lowest otherorganisms respectively february $\left(2105,33 \pm 530 \mathrm{ind} . / \mathrm{m}^{3}\right)$ and april $\left(549 \pm 202 \mathrm{ind} . / \mathrm{m}^{3}\right)$.

The dominant taxa in Manavgat River estuarin zone consist of Oithona nana, Clausocalanus arcuicornis, Acartia discaudata, Paracalanus parvus, Bosmina longirostris and Keretella cochleris and these species are eurohalin character types of zooplankton.
\end{abstract}

Key words: Manavgat River, Estuary, Zooplankton

\section{GİRIŞ}

Nehirağızları, nehirlerin denizlere açıldığı gel-git etkisindeki bölgelerdir. Bu bölgeler genel olarak kıyısal bölgenin dar olduğu alanlarda tatlı su ve deniz suyunun karışımından oluşan acı su (miksohalin) ortamlarıdır (Kocataş, 2006). Bu çalışmada Akdeniz'e dökülen Manavgat Nehri nehirağzı bölgesinin fizikokimyasal özellikleri, zooplanktonun çeşitliliği, aylara ve istasyonlara göre dağılımı ve bolluğu saptanmıştır. Zooplanktonda bulunan taksonların belirlenmesi, ülkemizin canlı çeşitliliğinin tespitine katkı sağlayacak, planktonla ilgili bulgular, örnekyerlerinin fizikokimyasal özellikleri ile ilişkilendirilecektir. Zooplankton sistematiğine yönelik şu ana kadar yapılmış birçok çalışma bulunmasına karşın bu çalışmaların çoğu ya tatlı su ya da denize yönelik çalışmalar olmuştur (Dönmez, 1998; Sever ve Mavili, 2002). Türkiye'de en yüksek biyolojik verimliliğin ortaya çıktığı nehirağızları ile ilgili az çalışma vardır (Işınibilir, 
2008; Bat vd., 2007; Baytut, 2010; Erdoğan, 2011).

\section{MATERYAL VE METOT}

Manavgat Nehri'nin kaynak suları Antalya-Akseki ilçesine bağlı Cevizli Beldesi'nin kuzeybatısındaki Akdağ ve Beyşehir Gölü’nün güneyindeki dağlardan çıkan kaynak suları ile Gembos kapalı havzasının güneyindeki suların birleşmesiyle oluşur. Deniz seviyesinden 1000-2000 metre yükseklikte olan Manavgat Nehri'nin başlangıcı yazın kuruyan küçük bir akarsu görünümündedir. Bu bölgedeki küçük akarsuların birleşmesiyle Manavgat Nehri oluşur. Yaklaşık $90 \mathrm{~km}$ uzunluğundaki bu nehir Manavgat ilçesinin ortasından geçerek Dalyan adı verilen yerde geniş bir nehirağzı ile Akdeniz'e dökülür. Özellikle nehirağzı bölgesinde çok sayıda tur teknesi ve piknik alanları az sayıda balık çiftlikleri bulunur (Küçük, 1997).

Ocak-Aralık 2009 tarihleri arasında, 12 ay süreyle ayda bir kez olmak üzere yürütülen örnekleme dönemi boyunca her bölge için nehirağzı bölgesinden 3, nehir ve deniz etkisinin olduğu bölgelerden birer olmak üzere toplam 5 istasyondan örnekleme yapılmıştır (Şekil 1).

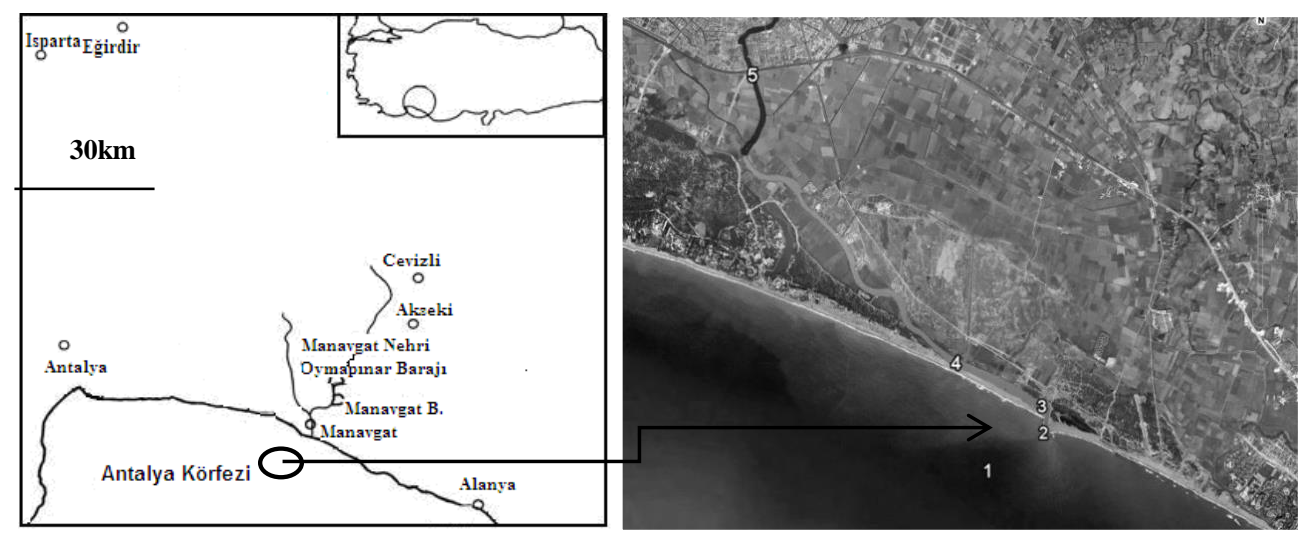

Şekil 1. Manavgat Nehri nehirağzı bölgesi ve istasyonlar (Google Earth, 2011)

Zooplanktonik organizmalar nehir ve nehirağzı bölgesi için yatay ve dikey plankton çekimi ile denizde ise 10,20 ve 30 metre derinliklerden dikey çekimler yapılarak elde edilmiştir. Plankton çekimlerinde ön ağız çap1 $17 \mathrm{~cm}$ ve ağ göz açıklığ1 $55 \mu \mathrm{m}$ olan Hensen tipte plankton kepçesi kullanılmıştır. Örneklerin alınmasında dikey çekimler için yerine sabitlenen bir tekneden, üzeri metrik olarak ölçeklendirilmiş bir ipin ucuna bağlanan plankton kepçesi ile dikey yönde, yaklaşık $1 \mathrm{~m} / \mathrm{s}$ hızla çekilmesiyle alınmıştır. Toplanan örnekler, 500 ml'lik plastik örnekleme kaplarına konulmuş, plankton kepçesinin bezine yapışan organizmalar su ile bir kez yıkanmış ve şişedeki örneğin üzerine eklenmiştir. Yatay çekimlerde 1,5-2 km/saat hızla 2-3 dk çekim yapılmış, toplanan örnekler yine 500 ml'lik plastik örnekleme kaplarına konulmuştur. Süzülen su miktarının hesaplanabilmesi için plankton kepçesine flowmetre (akıntı ölçer) takılmıştır. Toplanan plankton örnekleri, kavanozlara aktarıldıktan sonra \% 4'lük formaldehit çözeltisi ile tespitlenmiştir. (Özel, 1992). 
Rotifera'nın taksonomik incelemesinde ilgili kaynaklardan yararlanılmıştır (Edmondson, 1959-a; Elster and Ohle, 1974; Pontin, 1978; Koste, 1978-a, b, RutnerKolisko, 1974).

Rotifera dişındaki zooplanktonik organizmalar önce büyütmeli sterio mikroskopta bütün olarak incelenmiş, tanıya ilişkin özelliklerin ayrıntılı bir şekilde görülebilmesi için türler, 1/1 oranında hazırlanmış olan gliserin-alkol karışımında bir süre bekletilip saydamlaştırılmıştır. Bu şekilde fotoğrafları çekildikten sonra üzerinde bir damla gliserinalkol karışımı bulunan temiz bir lama alınarak incelenmiştir. Diseksiyon sonucu ortaya çıkan parçalar incelenerek tür tanıları yapılmıştır. (Harris et al., 2000 ; Bekleyen, 1997). Cladocera'nın taksonomik incelemesinde Edmondson (1959-b) , Smirnov (1996) Copepoda'nın taksonomik incelemesinde Rose (1933), Brodskii (1950), Grice (1962), Kasturirangan (1963), Frost and Fleminger (1968), Edmondson (1959-c), Bayly (1972), Newel and Newel (1977), Mazzocchi et al., (1995), Einsle (1996), Palomares et al., (1998), Boltovskoy (1999-a,b), Bradford-Grıeve (1999), Dussart and Defaye (2001), Özel (2003), Boxshall and Halsey (2004-a,b), Zununi (2006), den diğer organizmaların taksonomik incelenmesinde Tregouboff and Rose (1957), Boltovskoy, (1999-a,b), Perry (2003) den yararlanılmıştır.

\section{BULGULAR}

Tablo 1. Manavgat Nehri nehirağzı bölgesi, 2009 yılı Ocak-Haziran döneminde ayrımlı istasyonlarda belirlenen yüzey suyu nitelik değerleri (Ortalama \pm S.H., n =12)

\begin{tabular}{|c|c|c|c|c|c|}
\hline \multicolumn{6}{|c|}{ İstasyonlar } \\
\hline Parametre & 1. istasyon & 2. istasyon & 3. istasyon & 4. istasyon & 5. istasyon \\
\hline $\begin{array}{l}\text { Su sıcaklığı } \\
\left({ }^{\circ} \mathrm{C}\right)\end{array}$ & $22,94 \pm 1,22^{\mathrm{a}}$ & $15,12 \pm 0,55^{\mathrm{b}}$ & $14,53 \pm 0,63^{\mathrm{b}}$ & $14,02 \pm 0,62^{\mathrm{b}}$ & $13,74 \pm 0,69^{b}$ \\
\hline pH & $8,37 \pm 0,02^{\mathrm{a}}$ & $8,38 \pm 0,03^{\mathrm{a}}$ & $8,35 \pm 0,03^{\mathrm{a}}$ & $8,38 \pm 0,03^{\mathrm{a}}$ & $8,36 \pm 0,04^{\mathrm{a}}$ \\
\hline $\begin{array}{l}\text { Çöz. } \\
\text { Oksijen } \\
(\mathrm{mg} / \mathrm{l})\end{array}$ & $8,02 \pm 0,08^{c}$ & $8,29 \pm 0,05^{\mathrm{bc}}$ & $8,55 \pm 0,08^{b}$ & $9,50 \pm 0,13^{\mathrm{a}}$ & $9,94 \pm 0,16^{\mathrm{a}}$ \\
\hline $\begin{array}{l}\text { Tuzluluk } \\
\text { (ppt) } \\
\text { El. }\end{array}$ & $35,86 \pm 0,09^{\mathrm{a}}$ & $3,90 \pm 1,54 b$ & $0,68 \pm 0,20^{c}$ & $0,24 \pm 0,03^{c}$ & $0,15 \pm 0,01^{\mathrm{c}}$ \\
\hline $\begin{array}{l}\text { İletkenlik } \\
(\mu \mathrm{S} / \mathrm{cm})\end{array}$ & $52766,66 \pm 775,21^{\mathrm{a}}$ & $5485,36 \pm 1966,84^{\mathrm{b}}$ & $962,96 \pm 262,11^{\mathrm{c}}$ & $464,35 \pm 86,11^{\mathrm{c}}$ & $272,25 \pm 18,25^{\mathrm{c}}$ \\
\hline $\begin{array}{l}\text { Klorofil a } \\
\left(\mathbf{m g} / \mathbf{m}^{3}\right)\end{array}$ & $1,41 \pm 0,09^{\mathrm{b}}$ & $3,16 \pm 0,45^{\mathrm{a}}$ & $3,52 \pm 0,47^{\mathrm{a}}$ & $3,16 \pm 0,39^{a}$ & $1,09 \pm 0,09^{\mathrm{b}}$ \\
\hline $\begin{array}{l}\text { Secchi } \\
\text { Diski (m) }\end{array}$ & $12,41 \pm 0,58^{\mathrm{a}}$ & $1,14 \pm 0,04^{\mathrm{b}}$ & $1,17 \pm 0,06^{\mathrm{b}}$ & $0,94 \pm 0,04^{\mathrm{b}}$ & $0,88 \pm 0,03^{\mathrm{b}}$ \\
\hline
\end{tabular}


Tablo 2. Manavgat Nehri nehirağzı bölgesi, 2009 yılı Temmuz-Aralık döneminde ayrımlı istasyonlarda belirlenen dip suyu nitelik değerleri (Ortalama \pm S.H., $n=12$ )

\begin{tabular}{|c|c|c|c|c|c|}
\hline \multicolumn{6}{|c|}{ İstasyonlar } \\
\hline Parametre & $\begin{array}{c}\text { 1.istasyon } \\
(30 \mathrm{~m})\end{array}$ & 2. istasyon & 3. istasyon & 4. istasyon & 5. istasyon \\
\hline $\begin{array}{l}\text { Su } \\
\text { sıcaklığ }\left({ }^{\circ} \mathrm{C}\right)\end{array}$ & $22,71 \pm 1,22^{\mathrm{a}}$ & $20,59 \pm 1,50^{\mathrm{ab}}$ & $18,96 \pm 1,64^{\mathrm{abc}}$ & $16,90 \pm 1,47^{\mathrm{bc}}$ & $13,67 \pm 0,71^{\mathrm{c}}$ \\
\hline pH & $8,35 \pm 0,02^{\mathrm{a}}$ & $8,36 \pm 0,03^{\mathrm{a}}$ & $8,30 \pm 0,03^{\mathrm{a}}$ & $8,38 \pm 0,03^{\mathrm{a}}$ & $8,34 \pm 0,03^{a}$ \\
\hline $\begin{array}{l}\text { Çöz. Oksijen } \\
\text { (mg/l) }\end{array}$ & $7,88 \pm 0,06^{\mathrm{bc}}$ & $7,43 \pm 0,08 \mathrm{c}$ & $7,86 \pm 0,81^{b c}$ & $8,56 \pm 0,13^{b}$ & $9,60 \pm 0,14^{\mathrm{a}}$ \\
\hline $\begin{array}{l}\text { Tuzluluk } \\
\text { (ppt) }\end{array}$ & $35,83 \pm 0,08^{\mathrm{a}}$ & $20,49 \pm 4,03^{b}$ & $16,88 \pm 4,54^{b}$ & $0,6 \pm 0,21^{\mathrm{c}}$ & $0,19 \pm 0,02^{c}$ \\
\hline $\begin{array}{l}\text { El. İletkenlik } \\
(\mu \mathrm{S} / \mathrm{cm})\end{array}$ & $52958,33 \pm 746,75^{\mathrm{a}}$ & $27693,33 \pm 6118,60^{b}$ & $24729,49 \pm 6822,53^{\mathrm{b}}$ & $759,35 \pm 6470,39^{c}$ & $342,45 \pm 34,81^{\mathrm{c}}$ \\
\hline
\end{tabular}

Aynı satırdaki farklı harfler, istasyonlar arası farklılıkları göstermektedir $(\mathrm{P}<0,05)$

\section{Fiziksel ve Kimyasal Parametreler}

Araştırma süresince, Manavgat Nehri nehirağzı bölgesi’nde belirlenen, yüzey ve dip suyu nitelik değerlerinin istasyonlara göre değişimi tablo 1ve tablo 2 de verilmiştir.

Sıcaklık: Araştırma süresince, yüzey suyunda en yüksek sıcaklık değeri $31^{\circ} \mathrm{C}$ (ağustos, 1 . istasyon yüzey), en düşük $10,2{ }^{\circ} \mathrm{C}$ (ocak, 5. istasyon); dip sularında en yüksek sıcaklık değeri $31^{\circ} \mathrm{C}$ (ağustos, 2. istasyon), en düşük ise $10{ }^{\circ} \mathrm{C}$ (ocak, 5. istasyon) olarak ölçülmüştür (Şekil 2). Yüzey ve dip suyu arasındaki farklılık ağustos ayında önemli $(\mathrm{P}<0,05)$, diğer aylarda önemsiz bulunmuştur $(\mathrm{P}>0,05)$.

\section{1.İstasyon}

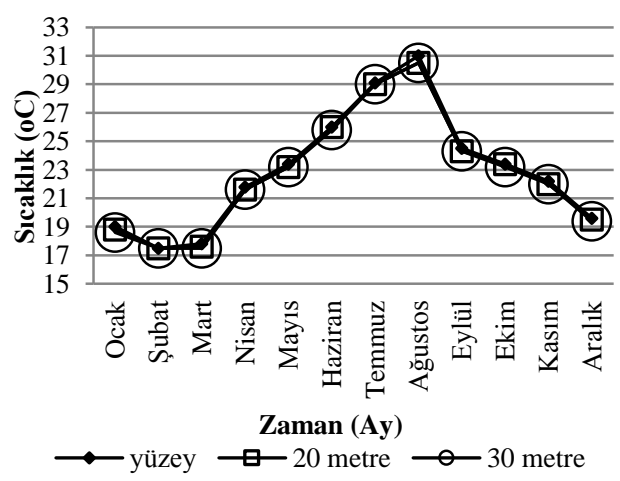

2. İstasyon

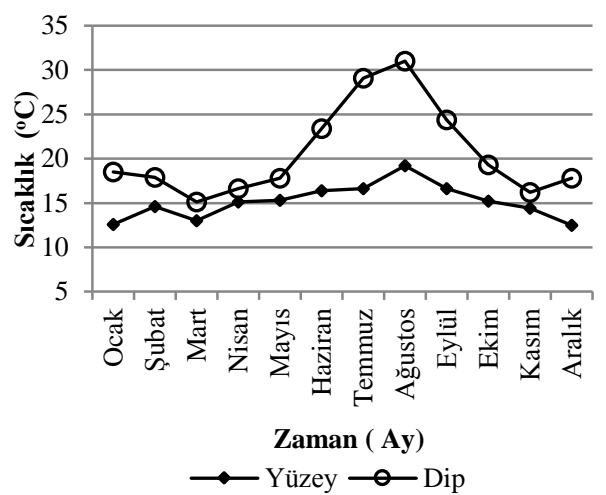



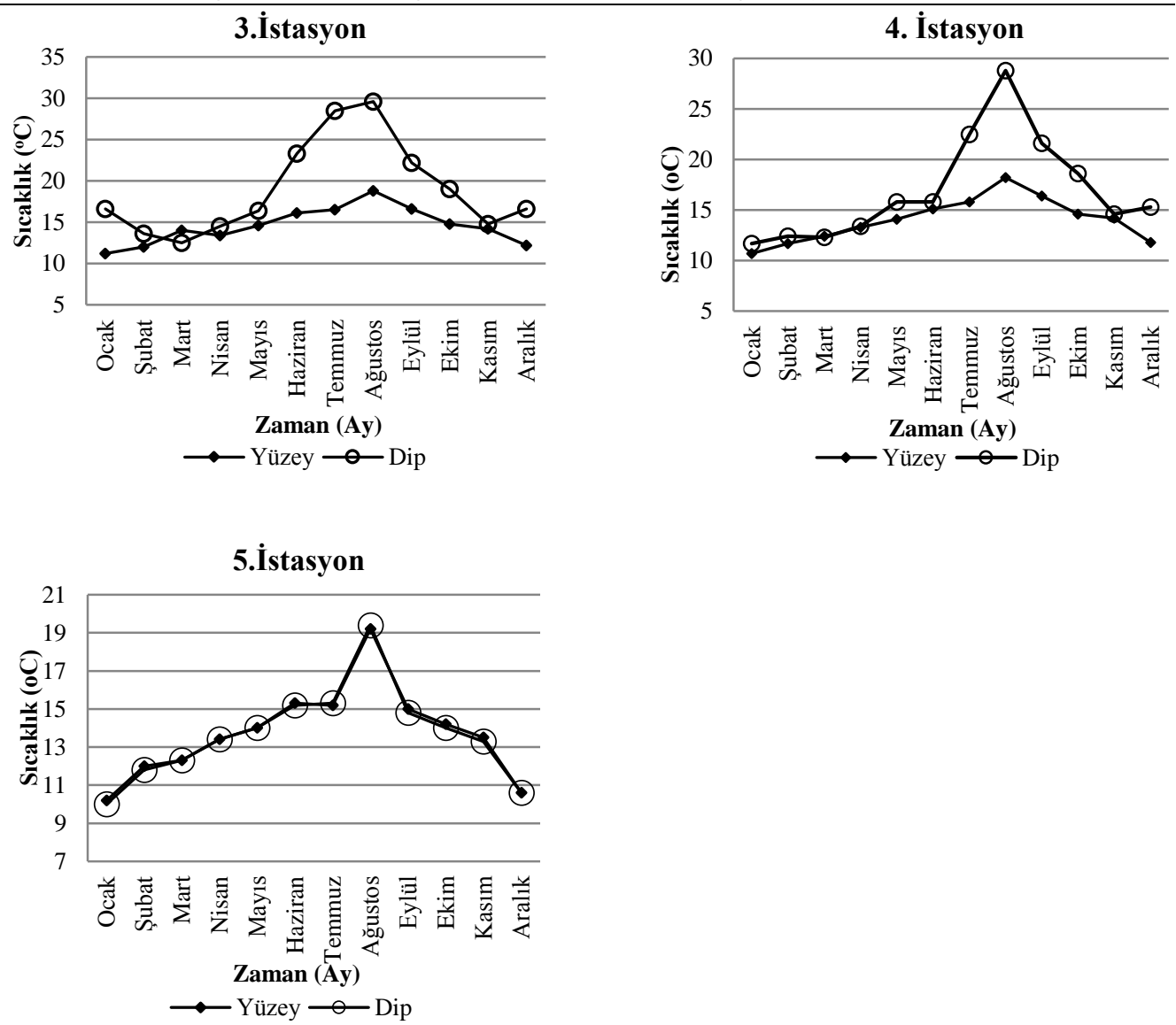

Şekil 2. Manavgat Nehri nehirağzı bölgesi yüzey ve dip suyu sıcaklık değerleri $\left({ }^{\circ} \mathrm{C}\right)$

Tuzluluk:Yüzey sularında en yüksek tuzluluk değeri 36,4 ppt (eylül, 1.istasyon yüzey), en düşük 0,1 ppt (aralık, 5. istasyon), dip sularında en yüksek 36,3 ppt (eylül, 1.istasyon 20,30 m), en düşük 0,1 ppt (nisan, mayıs, haziran, 4. istasyon, nisan, mayıs, haziran, ocak, kasım ve aralık, 5. /istasyon) olarak belirlenmiştir (Şekil 3.). Yüzey ve dip suyu arasındaki farklılık önemsiz bulunmuştur $(\mathrm{P}>0,05)$. 


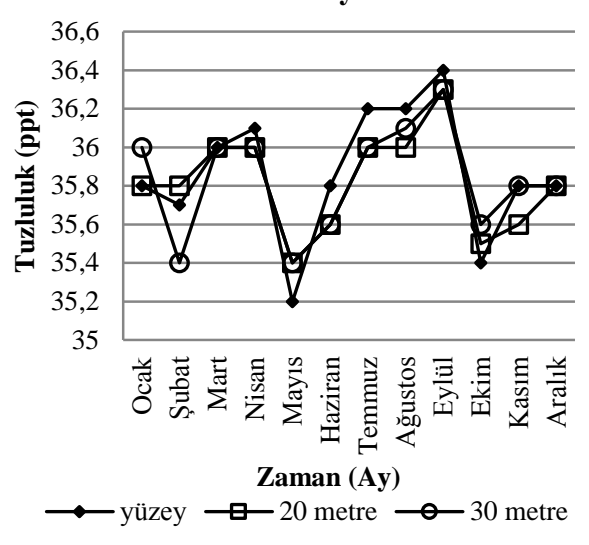

3.İstasyon
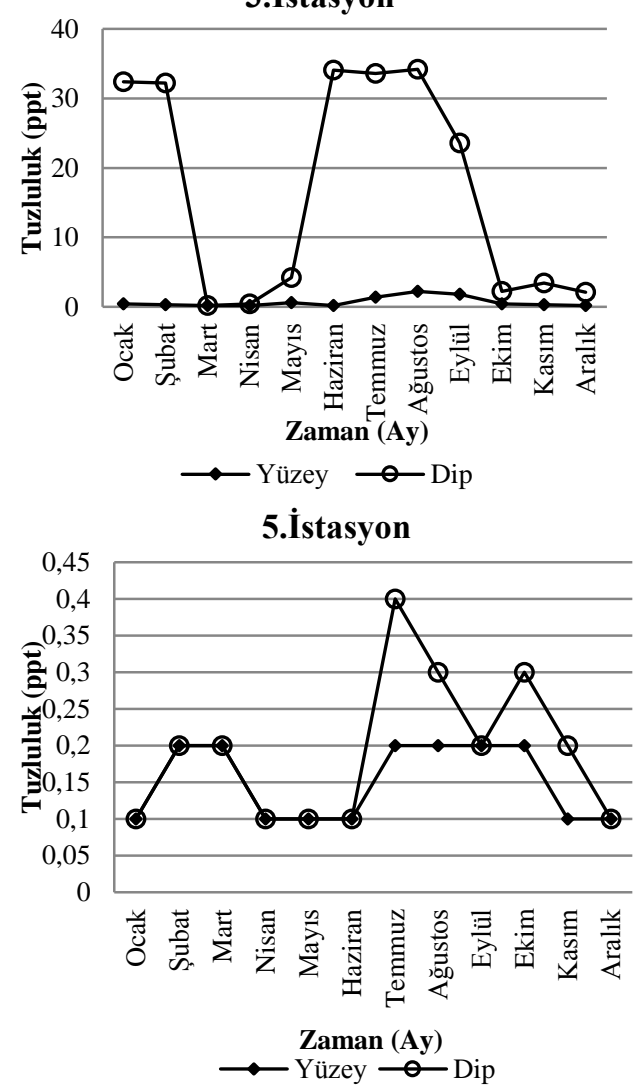

2. istasyon

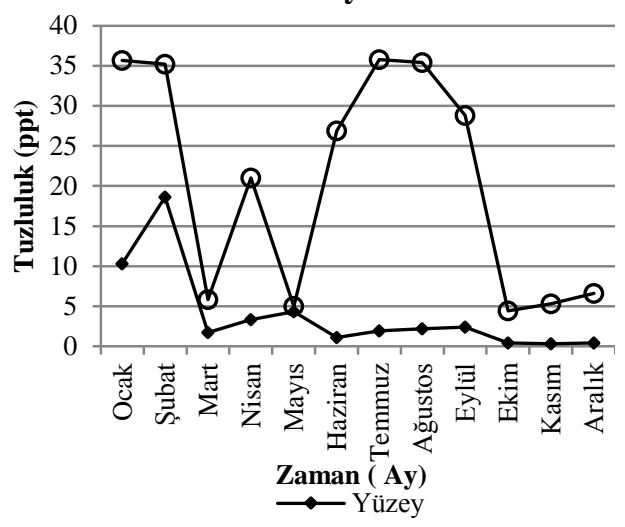

4. İstasyon

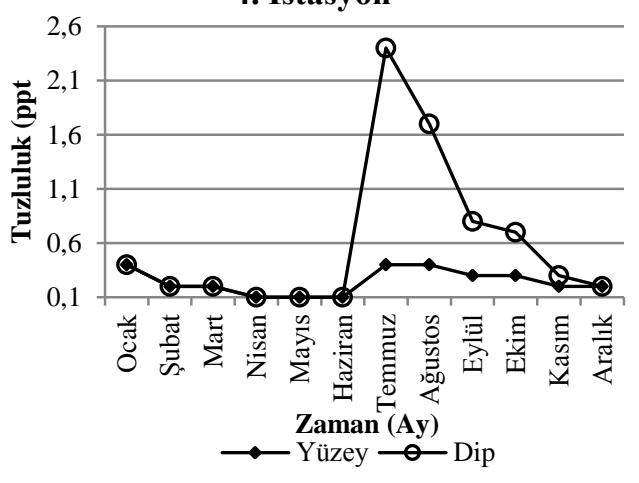

Şekil 3. Manavgat Nehri nehirağzı bölgesi yüzey ve dip suyu tuzluluk değerleri (ppt)

Çözünmüş Oksijen: Çözünmüş oksijen değeri yüzey sularında en yüksek 10,9 mg/1 (şubat, 5. istasyon), en düşük 7,64 mg/l (eylül, 1. istasyon yüzey), dip sularında en yüksek $10,6 \mathrm{mg} / 1$ (şubat, 5 . istasyon), en düşük $7,3 \mathrm{mg} / 1$ (ağustos, 3. ve 4. istasyon $30 \mathrm{~m}$ )olarak belirlenmiştir (Şekil 4). Yüzey ve dip suyu arasındaki farklılık önemsiz bulunmuştur $(\mathrm{P}>0,05)$. 

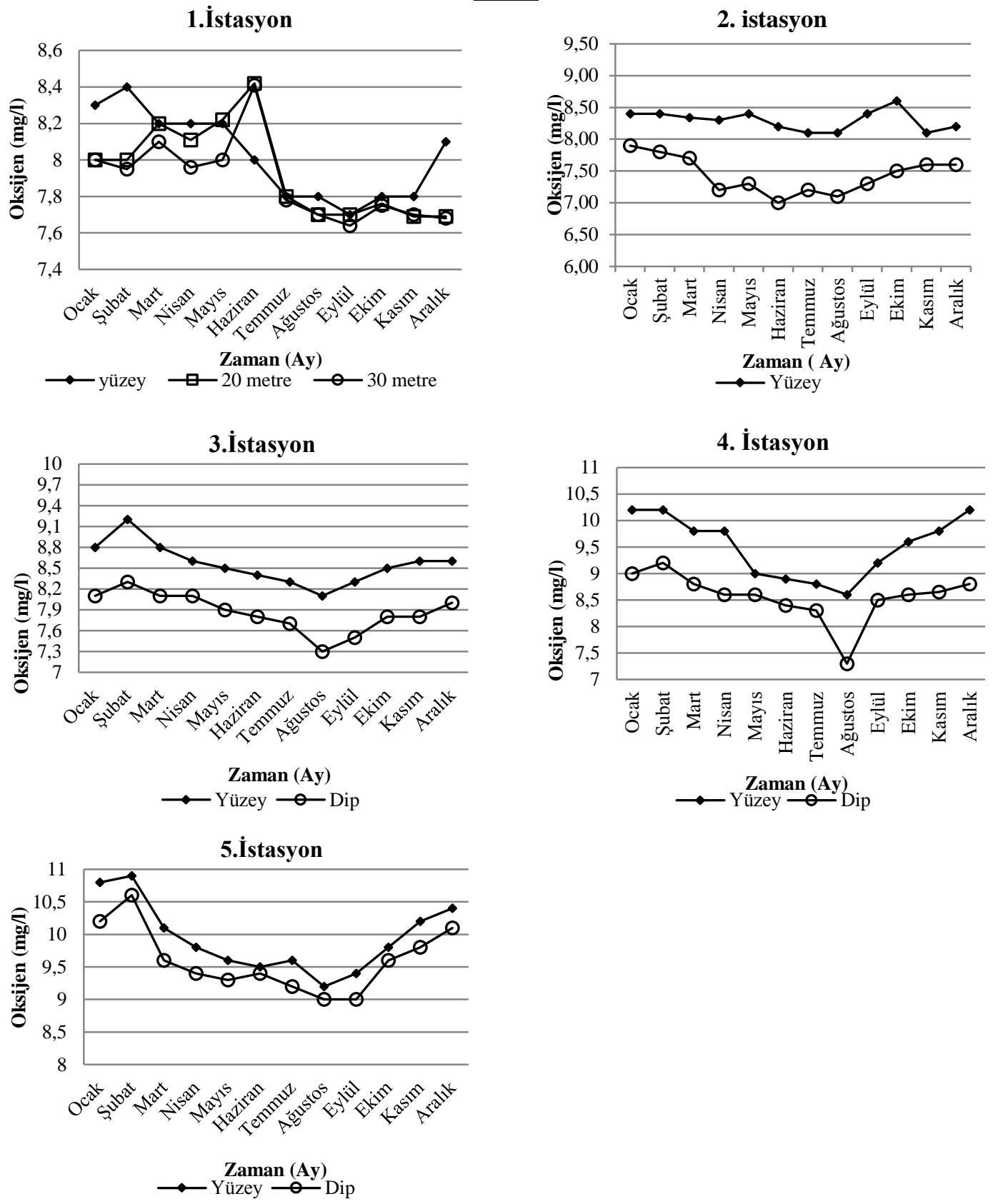

Şekil 4. Manavgat Nehri nehirağzı bölgesi yüzey ve dip suyu çözünmüş oksijen değerleri (mg/l)

\section{Zooplankton Taksonları}

Manavgat Nehri nehirağzı bölgesinde zooplanktonda Rotifera'dan 22, Cladocera'dan 11, Copepoda'dan 32, Cnidaria, Foraminifera, Tintinida, Cirripedia, Bivalvia, Polychaeta, Chaetognatha, Decapoda, Ostracoda, Ihtiyoplankton'ndan 1'er olmak üzere toplam 75 takson belirlenmiş olup bu taksonlar aşağıda sınıflandırılmıştır. 
Tablo 3.Manavgat Nehri nehirağzı bölgesinde zooplankton taksonları

\section{ROTIFERA}

Euchlanis dilatata Ehr., 1832

Euchlanis deflexa (Gosse, 1851)

Trichotria pocillum (Müller, 1773)

Macrochaetus collinsi (Gosse, 1867)

Colurella uncinata (Müller, 1773)

Colurella sp. (Müler, 1773)

Lepadella ovalis (Müler, 1786)

Asplanchna priodonta Gosse, 1850

Testudinella patina (Herman, 1783)

Brachionus plicatilis (Müler, 1786)

Keratella cochlearis (Gosse, 1851)

Keratella quadrata (Müller, 1786)

Lecane luna (Müler, 1776)

Lecane lunaris (Ehr., 1832)

Cephalodella gibba (Ehr., 1838)

Trichocerca longiseta (Schrank, 1802)

Ascomorpha ovalis (Carlin, 1943)

Gastropus stylifer (Imhof, 1891)

Rotaria sp.

Synchaeta sp.

Polyarthra vulgaris (Carlin, 1943)

Testudinella patina (Herman, 1783)

\section{CLADOCERA}

Ceriodaphnia pulchella Sars, 1862

Daphnia longispina O. F. Müller, 1785

Daphnia cucullata (Sars 1862)

Diaphanosoma sp.

Bosmina longirostris (O. F. Müller, 1785)

Moina micrura Kurz, 1874

Chydorus sphaericus (O. F. Müller, 1776)

Penilia avirostris (Dana, 1849)

Evadne spinifera P.E.Muller, 1867

Evadne nordmanni (Lovén, 1836)

Podon polyphemoides (Leuckart,1859)

\section{COPEPODA}

Clausocalanus arcuicornis (Dana, 1849)

Clausocalanus furcatus (Brady, 1883)

Pseudodiaptomus marinus (Sato, 1913)

Acartia clausi (Giesbrecht, 1889)
Acartia latisetosa (Giesbrecht, 1892)

Acartia discaudata Giesbrecht, 1892)

Acartia negligens (Dana, 1849)

Acartia grani (Sars, 1904)

Paracalanus parvus (Claus, 1863)

Paracalanusaculeatus (Giesbrecht,1888)

Paracalanusnanus (Sars, 1907)

Calocalanusstyliremis Giesbrecht, 1888

Acrocalanus sp.

Temora stylifera (Dana, 1849)

Candacia armata Boeck, 1872

Labidocera sp.

Pontella mediterranea (Claus, 1863)

Pleuromamma gracilis (Claus, 1863)

Mecynocera clausi (Thompson, 1888)

Centropages furcatus (Dana, 1852)

Centropages kroyeri (Giesbrecht,1892 )

Centropages violaceus (Claus, 1863)

Phaenna spinifera (Claus, 1863)

Oithona nana (Giesbrecht, 1892)

Oithona plumifera (Baird, 1843)

Oithona helgolandica (Claus, 1863)

Cyclops abyssorum (Sars, 1863)

Coryceaus sp.

Oncaeamediterranea (Claus, 1863)

Oncaea minuta (Giesbrecht, 1892)

Euterpina acutifrons (Dana, 1852)

Microsetella rosea (Dana, 1848)

DİĞERLERİ

Cnidaria (Actinula larvasi)

Foraminifera

Tintinida

Cirripedia

Bivalvia

Polychaeta

Chaetognatha

Ostracoda

Decapoda (Zoea)

Ihtiyoplankton 
Zooplankton gruplarına ilişkin yoğunluk ve oranın aylara göre değişimi tablo 4'de verilmiştir.

Tablo 4. Zooplanktonun farklı gruplara bağlı olarak yoğunluğun aylara göre değişimi

\begin{tabular}{lllll}
\hline \hline & Copepoda & Rotifer & Cladocera & Diğer \\
\hline Ocak & $4771 \pm 1104^{\mathrm{cd}}$ & $1686 \pm 600^{\mathrm{a}}$ & $204 \pm 71^{\mathrm{bcd}}$ & $781,89 \pm 167^{\mathrm{b}}$ \\
Şubat & $4712,33 \pm 1161^{\mathrm{cd}}$ & $1820 \pm 641^{\mathrm{a}}$ & $456 \pm 172^{\mathrm{bcd}}$ & $753,83 \pm 168^{\mathrm{b}}$ \\
Mart & $2160 \pm 726^{\mathrm{d}}$ & $644 \pm 298^{\mathrm{a}}$ & $506 \pm 230^{\mathrm{bcd}}$ & $638,33 \pm 157^{\mathrm{b}}$ \\
Nisan & $2924,67 \pm 1018^{\mathrm{d}}$ & $904 \pm 214^{\mathrm{a}}$ & $576 \pm 161^{\mathrm{bcd}}$ & $549,49 \pm 202^{\mathrm{b}}$ \\
Mayıs & $3152 \pm 1000^{\mathrm{d}}$ & $787 \pm 299^{\mathrm{a}}$ & $616 \pm 206^{\mathrm{bcd}}$ & $588,06 \pm 173^{\mathrm{b}}$ \\
Haziran & $7298,67 \pm 2356^{\mathrm{bcd}}$ & $790 \pm 195^{\mathrm{a}}$ & $1166,67 \pm 323^{\mathrm{abc}}$ & $684 \pm 143^{\mathrm{b}}$ \\
Temmuz & $21167,33 \pm 7513^{\mathrm{ab}}$ & $934 \pm 263^{\mathrm{a}}$ & $1979,33 \pm 397^{\mathrm{ab}}$ & $2105 \pm 530^{\mathrm{a}}$ \\
Ăgustos & $22883 \pm 8156^{\mathrm{a}}$ & $720 \pm 266^{\mathrm{a}}$ & $2279 \pm 386^{\mathrm{ab}}$ & $2065 \pm 509^{\mathrm{a}}$ \\
Eylül & $21069,33 \pm 7249^{\mathrm{abc}}$ & $705 \pm 283^{\mathrm{a}}$ & $2118,67 \pm 354^{\mathrm{ab}}$ & $2081 \pm 508^{\mathrm{a}}$ \\
Ekim & $17870,67 \pm 7273^{\mathrm{bcd}}$ & $685 \pm 283^{\mathrm{a}}$ & $1921 \pm 355^{\mathrm{abc}}$ & $2051 \pm 508^{\mathrm{a}}$ \\
Kasım & $14534,67 \pm 4292^{\mathrm{bcd}}$ & $905 \pm 377^{\mathrm{a}}$ & $1467,67 \pm 255^{\mathrm{abc}}$ & $1838 \pm 501^{\mathrm{a}}$ \\
Aralık & $10425,33 \pm 3092^{\mathrm{bcd}}$ & $884 \pm 318^{\mathrm{a}}$ & $1093,33 \pm 261^{\mathrm{abc}}$ & $1634 \pm 523^{\mathrm{a}}$ \\
\hline \hline
\end{tabular}

Aynı sütundaki farklı harfler aylar arasındaki farklılığı göstermektedir $(\mathrm{P}<0,05)$

Kopepod yoğunluğu en yüksek ağustos $\left(22883 \pm 8156 \mathrm{org} / \mathrm{m}^{3}\right)$, en düşük mart $\left(2160 \pm 726 \mathrm{org} / \mathrm{m}^{3}\right)$; rotifer yoğunluğu en yüksek şubat $\left(1820 \pm 641 \mathrm{org} / \mathrm{m}^{3}\right)$, en düşük eylül $\left(644 \pm 298 \mathrm{org} / \mathrm{m}^{3}\right)$; kladoser yoğunluğu en yüksek ağustos $\left(2279 \pm 386 \mathrm{org} / \mathrm{m}^{3}\right)$, en düşük ocak $\left(204 \pm 71 \mathrm{org} / \mathrm{m}^{3}\right)$; diğer organizmaların yoğunluğu en yüksek şubat $(2105 \pm 530$ org/ $\left.\mathrm{m}^{3}\right)$, en düşük nisan $\left(549,49 \pm 202 \mathrm{org} / \mathrm{m}^{3}\right)$ aylarında belirlenmiştir (Şekil 5).

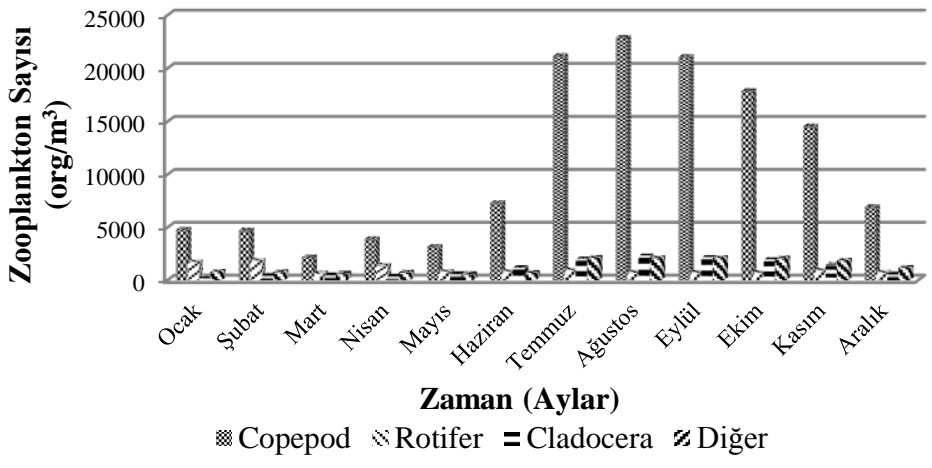

Şekil 5. Zooplankton grupları yoğunluğunun aylara göre değişimi 
Manavgat Nehri nehirağzı bölgesi 2.,3.,4. ve 5.istasyonlarda (deniz bölgesi hariç) yatay çekimler sonucu elde edilen zooplankton gruplarının ortalama yoğunluğunun istasyonlara bağl1 olarak değişimi şekil 6'da verilmiştir. En yüksek yoğunluk 3. istasyonda Copepodlarda görülmüştür $\left(14191,66 \pm 3266 \mathrm{org} / \mathrm{m}^{3}\right)$. En yüksek zooplankton yoğunluğu ortalamas1 $17918,33 \pm 3670 \mathrm{org} / \mathrm{m}^{3}$ ile 3 . istasyonda görülmüştür.

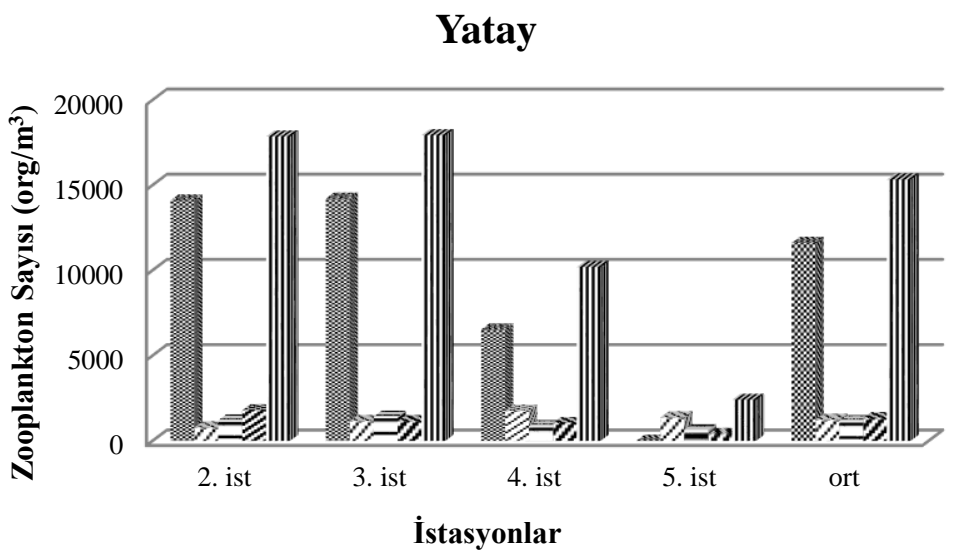

\% Copepod $₫$ Rotifer = Cladocera $\$$ Diğer II Toplam

Şekil 6. Manavgat Nehri nehirağzı bölgesi 2.,3.,4. ve 5. istasyonlarda (deniz bölgesi hariç) yatay çekimler sonucu elde edilen zooplankton gruplarının ortalama yoğunluğu $\left(\mathrm{org} / \mathrm{m}^{3}\right)$

Manavgat Nehri nehirağzı bölgesi 2.,3.,4. ve 5.istasyonlarda (deniz bölgesi hariç) dikey çekimler sonucu elde edilen zooplankton gruplarının ortalama yoğunluğunun istasyonlara/bağlı olarak değişimi şekil 7'de verilmiştir. En yüksek yoğunluk Copepodlarda görülmüştür. (3. İstasyon, $25635,83 \pm 5966 \mathrm{org} / \mathrm{m}^{3}$ ). En yüksek zooplankton yoğunluğu ortalaması $29732,5 \pm 6555 \mathrm{org} / \mathrm{m}^{3}$ ile 3 . istasyonda görülmüştür

\section{Dikey}

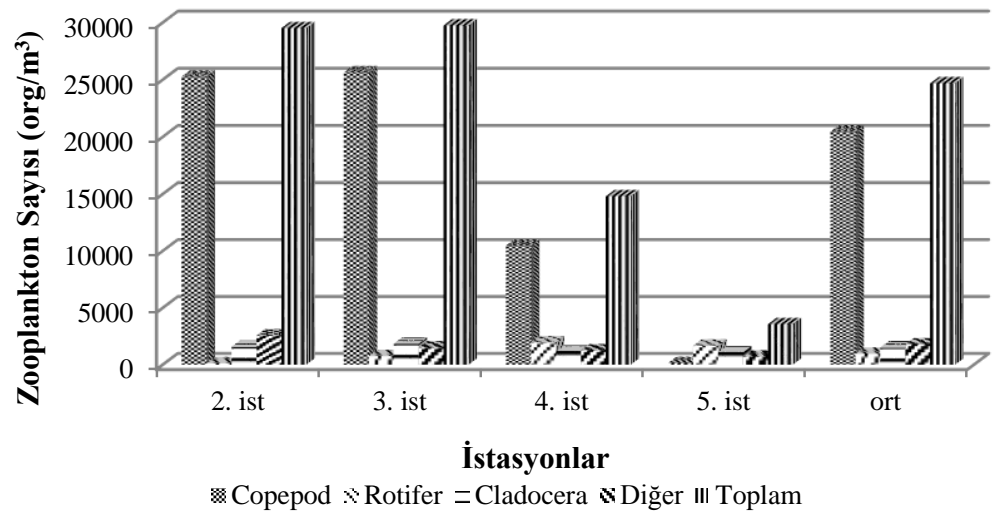

Şekil 7. Manavgat Nehri nehirağzı bölgesi 2.,3.,4. ve 5.istasyonlarda (deniz bölgesi hariç) yatay çekimler sonucu elde edilen zooplankton gruplarının ortalama yoğunluğu $\left(\mathrm{org} / \mathrm{m}^{3}\right)$ 
1. istasyonda (deniz bölgesi) 10, 20 ve 30 metre derinliklerdeki zooplankton yoğunlukları Şekil 8.'de verilmiştir. En yüksek zooplankton yoğunluğuna $\left(14640 \mathrm{org} / \mathrm{m}^{3}\right)$ ağustos ayında 20 metre derinlikte rastlanılmıştır. Derinlikler arasındaki farklılık önemli bulunmamıştır $(\mathrm{P}>0,05)$.

\section{1. İstasyon}

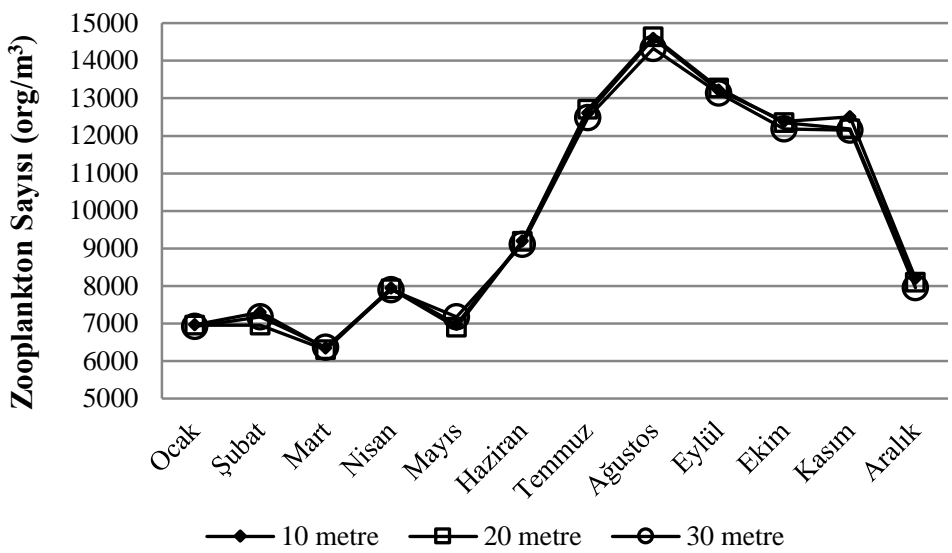

Şekil 8. 1. istasyon (deniz bölgesi)'nda 10, 20 ve 30 metre derinliklerdeki zooplankton yoğunlukları( org $\left./ \mathrm{m}^{3}\right)$

Tüm istasyonlarda yatay ve dikey çekimlerin ortalaması üzerinden zooplanktonun yıl boyu göstermiş olduğu gelişim eğrisi incelendiğinde en yüksek zooplankton miktarı ağustos ayında gerçekleşmiştir. Toplam zooplankton yoğunluğunun en düşük olduğu ay mayıs ayıdır. Ağustos ayındaki toplam zooplankton yoğunluğu $27947 \pm 8780,45 \mathrm{org} / \mathrm{m}^{3}$ olarak belirlenmiştir (Şekil 9).

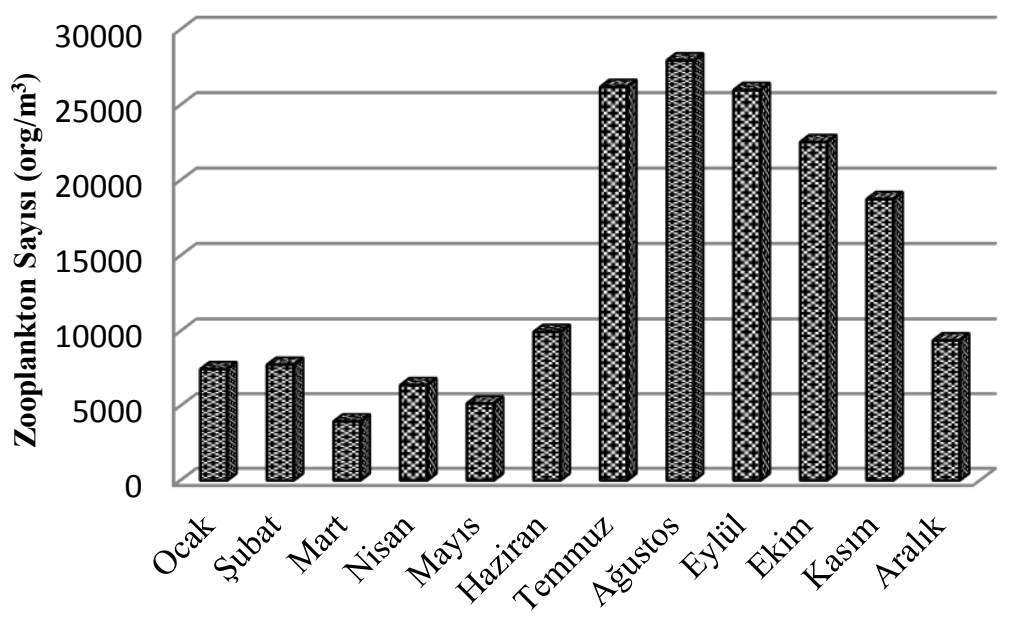

Şekil 9.Toplam zooplankton yoğunluğunun aylara göre değişimi $\left(\mathrm{org} / \mathrm{m}^{3}\right)$ 


\section{Sık Görülen Türler}

Manavgat Nehri nehirağzı bölgesinde araştırma süresince sık görülen türler ve bu türlerin aylara bağlı olarak birey sayıları Şekil 10' da verilmiştir.

Clausocalanus arcuicornis

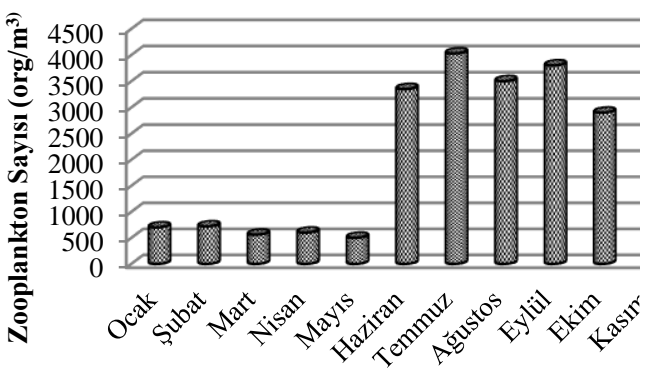

Zaman (Aylar)

Acartia discaudata
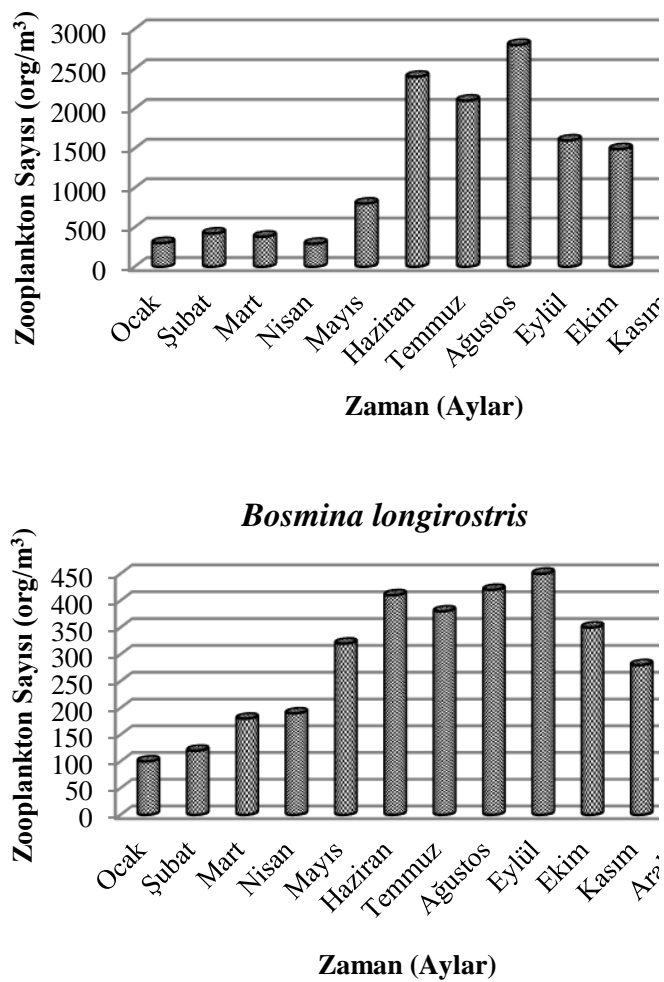

Paracalanus parvus

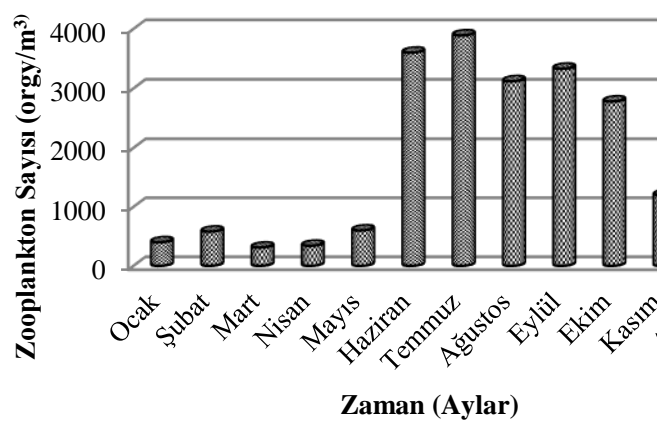

Oithona nana

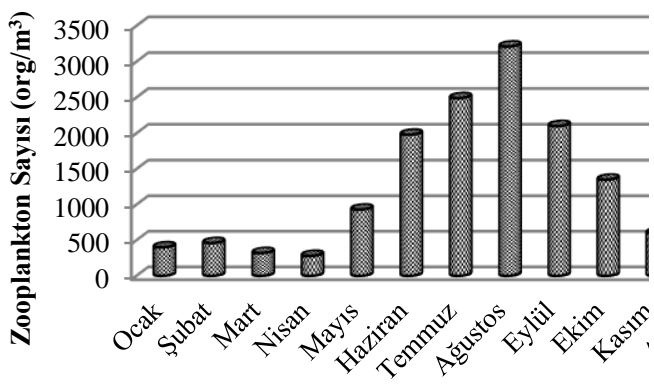

Zaman (Aylar)

Keratella cochlearis

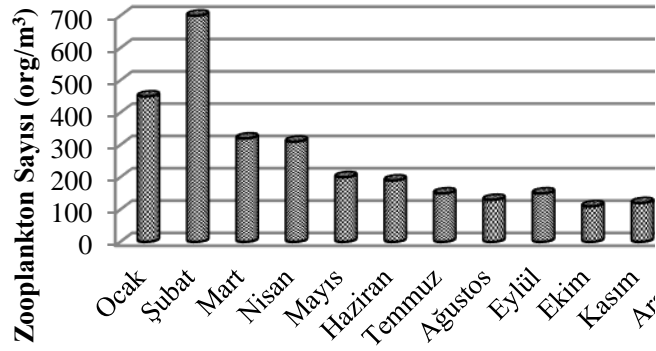

Zaman (Aylar)

Şekil 10. Araştırma süresince sık görülen türler 


\section{TARTIŞMA VE SONUÇ}

Nehirağzı bölgeleri deniz ve tatlı suyun birleştiği bölgeler olup, bu bölgelerde nehrin tatlı suları yoğunluk farkından dolayı su sütununun üst kısmında bulunurken, denizin daha yoğun olan tuzlu suları suyun aşağı kesiminden nehirağzı bölgesine doğru ilerler. $\mathrm{Bu}$ nedenle araştırmamızda yapılan fiziko-kimyasal ölçümler ve planktonla ilgili örneklemeler bu durumu yansıtacak şekilde yapılmıştır (dip ve yüzey kesimi).

Manavgat Nehri'nde dip suyu sıcaklık değerleri yüzey suyu değerlerine göre deniz bölgesi hariç (1. istasyon) tüm istasyonlarda yıl boyu daha yüksektir. Kış aylarında tatlı suyun debi artışına bağlı olarak nehrin etkisi fazla iken, yaz aylarında bu suyun debisinin azalmasıyla, deniz etkisinin artışına paralel yüzey ve dip suyu sıcaklık farkı yükselmiştir. Bu farkl1lık özellikle 2., 3. ve 4. istasyonlarda daha belirgin gözükmektedir. Yüzey ve dip suyu arasındaki sıcaklık farklılığı Ağustos ayında önemli $(\mathrm{P}<0,05)$ diğer aylarda önemsiz bulunmuştur $(\mathrm{P}>0,05)$. Benzer şekilde yaz aylarında denizin etkisinin artmasıyla dip suyu tuzluluğu 2. ve 3. istasyonlarda 35 ppt'nin üzerine çıkmaktadır. Yüzey ve dip suyu arasındaki farklılık önemsiz bulunmuştur $(\mathrm{P}>0,05)$. Bölgede mart ve nisan aylarında görülen sel yüzünden tuzluluk değerleri dip ve yüzey sularında düşüktür. Nehirağzı'nda çözünmü̈ş oksijen derişimi sıcaklığın azaldığı kış aylarında yükselmiş, sıcaklığın yükseldiği ve tuzluluğun arttığ 1 yaz döneminde ve sonbaharın ilk aylarında azalmıştır. Yüzey sularının nehir etkisinde olmasından dolayı çözünmüş oksijen derişimi dip sularına göre yüksektir. Nehirağzından yukarı doğru gidildikçe çözünmüş oksijen derişimi artmıştır.

Manavgat Nehri nehirağzı bölgesinde zooplanktonda Rotifera'dan 22, Cladocera'dan 11, Copepoda'dan 32, Cnidaria, Foraminifera, Tintinida, Cirripedia, Bivalvia, Polychaeta, Chaetognatha, Decapoda, Ostracoda, Ihtiyoplankton'ndan 1'er olmak üzere toplam 75 takson belirlenmiştir.

Kopepodlar yıl boyu zooplanktonun baskın kümesi olmuş, ocak ve şubat ayında toplam zooplanktonun sirasiyla \% 64 ve \% 61'ini yaz döneminde bölgede tuzluluğun artmasiyla toplam zooplanktonun temmuz'da \% 81'ini, ağustos'ta \% 82'sini, eylül'de \% 81'ini ve ekim'de \% 79'unu oluşturduğu belirlenmiştir.Vieira et al. (2003) toplam zooplanktonun \% 60'ın1, Khalil and El-Rahman (1997) \% 75'ini, Naumenko, (2009) \% 56'sını kopepodların oluşturduğu belirlemiştir.

Manavgat'da 32 kopepod türü belirlenmiştir. Sözü edilen bölgenin 2., 3. ve 4. örnekyerleri deniz ve nehrin birleşme noktası olup acısu özelliği gösteren bölgedir. $\mathrm{Bu}$ örnekyerlerinde genel olarak görülen türler Oithona nana, Clausocalanus arcuicornis, Clausocalanus furcatus, Acartia discaudata, Calocalanus styliremis, Pleuromamma gracilis, Temora stylifera,Centropages furcatus, Centropages kroyeri, Coryceaus sp. Euterpina acutifrons, Paracalanus parvus, Oithona nana, Oithona plumifera, Oncaea mediterrenae, Oncaea minuta/türleridir.

Kalanoid kopepodlardan Paracalanidae, Clausocalanidae and Temoridae tür sayıs1 ve biomas bakımından kalanoid kopepodlar arasında baskın familyalardır. (Işinibilir et al., 2008, Miyashita et al, 2009).Yapılan bu çalışmada Clausocalanus cinsine ait iki tür (Clausocalanus arcuicornis, C. furcatus). Belirlenmiştir. Clausocalanus arcuicornis en yüksek birey sayısına sahip takson olmuştur.(Temmuz, $4030 \mathrm{org} / \mathrm{m}^{3}$ ).Paracalanus parvus Temmuz ay1'nda $3980 \mathrm{org} / \mathrm{m}^{3}$ olarak belirlenmiştir.

Victoria Körfezi östarin sistemi (Güneydoğu Brezilya) 'nde Paracalanus parvus, Paracalanus quasimodo ve Parvocalanus crassirostris nehirağzı bölgesinindaha alt kısımlarında daha çok yoğunluğa ulaşmıştır (Sterza and Fernandez, 2006). Manavgat 
nehirağzı bölgelerinde 5 istasyondan alınan örneklemelerde Paracalnus cinsine ait toplam 3 tür (Paracalanus parvus, P.aculetus, $P$. nanus) tespit edilmiştir. Özellikle P. parvus türü örihalin karekterde bir tür olup nehirağzı bölgesinde baskın olarak saptanmıştır. Paracalanus cinsine ait türlere yıl boyu rastlanılmıştır.

Oithona cinsine ait türlerin tipik östrain bölge türleri olduğu, nehirağzı bölgesinin yukarı kesimlerini daha çok yeğledikleri bilinmektedir (Vieira et al., 2003,Sterza and Fernandez, 2006). Çalışmamızda Oithona cinsine ait 3 tür (Oithona helgolandica, Oithona nana ve Oithona plumifera) tespit edilmiştir. Bu türler yukarıdaki çalışmalarda belirtilen nehirağzı bölgesine özelleşmiş olan Oithona cinsine ait türlerdir. Manavgat nehirağz1 bölgesinde 2., 3. ve 4. örnekyerlerinde Oithona nana ve Oithona plumifera baskın taksonlar olarak görülürken Oithona helgolandica türüne sadece 1. istasyonda rastlanılmıştır.

Manavgat Nehri nahirağzı bölgesinde 22 rotifer türü tespit edilmiş Euchlanis dilatata, Colurella uncinata, Lepadella ovalis, Keratella cochlearis, Keratella quadrata, Asplanchna priodonta, Cephalodella gibba, Polyarthra vulgaris, Testudinella patina yaygın olarak gözlenirken Keratella cochlearis baskın takson olarak tespit edilmiştir.

Araştırmamızda bulunan türler daha önce yapılan benzer çalışmalarda bulunan nehir ve nehirağzı bölgelerine uyum yapmış türlerdendir (Crump and Baross, 1996; Holst et al., 1998). Nehirağzında yüksek yoğunluklara ulaşan türler tuzluluk değişimine hoşgörüsü geniş olan (örik) rotifer türleridir. Manavgat bölgesinde en yüksek yoğunluğa ulaşan Keratella cochlearis'in tuzlulukla ilişkisinin olumlu yönde olduğu yapılan çalışmalarda belirtilmiştir (Holst et al., 1998; Azemar et al., 2010).

Manavgat nehirağzı bölgesinde 5 istasyondan alınan örneklerde Ceriodaphnia pulchella, Daphnia longispina, Daphnia cucullata, Diaphanosoma sp., Moina micrura, Chydorus sphaericus, Bosmina longirostris, Bosmina fatalis, Penilia avirostris, Evadne spinifera, E.nordmanni ve Podon polyphemoides olmak üzere toplam 12 tür belirlenmiştir. Ceriodaphnia pulchella, Daphnia longispina, Daphnia cucullata, Diaphanosoma sp. Moina micrura, Chydorus sphaericus, Bosmina fatalis ve Alona sp.türleri daha çok tuzluluğun düşük olduğu istasyonlarda görülürken, Bosmina longirostris, Evadne spinifera, E.nordmanni ve Penilia avirostris 2,3 ve 4. istasyonlarda, Podon polyphemoides ise sadece deniz bölgesinde (1. istasyonda) tespit edilmiştir. Nehirağzı bölgesinde bulunan türler nehirağzı bölgesinde yapılan çalışmalarda tanımlanan örihalin karakterdeki türlerdir(Naumenko, 2009(Sautour et al., 1996). (Puelles et al., 2004) Chícharo et al., 2001).

\section{TEŞEKKÜRLER}

Çalışmamıza 1730-D-07 nolu proje ile destek veren Süleyman Demirel Üniversitesi Bilimsel Araştırmalar Başkanlığına teşekkür ederiz. 


\section{KAYNAKLAR}

Azemar, F., Marıs, T., Mialet, B., Segers H., Damme S.F., Meire, P., Tackx , M., 2010. Rotifers in the Schelde Estuary (Belgium):A test of taxonomic relevance. Journal Of Plankton Research, 32 (7), 981-997 p.

Bat, L., Sahin, F., Ustun, F., Kideys, A., Satilmis, H.H. (2007). The Qualitative and Quantitative Distribution in Phytoplankton and Zooplankton of Southern Black Sea of Cape Sinop, Turkey in 1999-2000. IEEE Oceans'07, IEEE Catalogue Number: O7EX1527C; ISBN Number: 1-4244-0635-8; Library on Congress: 2006932314, 6 p.Doi: 10.1109/Oceanse.2007.4302224.

Bayly, I.A.E., 1972. The Non-Marine Centropagidae (Copepod: Calanoida) of the World. SPB Academic Publishing, Netherlands. 1-30 p.

Baytut, O., Gönülol, A., Koray, T., 2010. Temporal Variations of Phytoplankton in Relation to Eutrophication in Samsun Bay, southern Black Sea. Turkish Journal of Fisheries and Aquatic Sciences 10: 363-372.

Bekleyen, A., 1997. Devegeçidi ve Göksu Barajlarında Dağılış Gösteren Zooplankton Gruplan Üzerinde Sistematik ve Ekolojik Çalışmalar. Dicle Üniversitesi Fen Bilimleri Enstitüsü Biyoloji Anabilim Dalı, Doktora Tezi, Diyarbakır.

Boltovskoy, D., 1999-a. South Atlantic Zooplankton Vol:1. Backhuys Publishers, Leiden. 870-1705p.

Boltovskoy, D., 1999-b. South Atlantic Zooplankton Vol:2. Backhuys Publishers, Leiden.1-870p.

Boxshall, G.A., Halsey, S.H., 2004 a. An introduction to Copepod Diversity. Part I, The Ray Society Instituted. London, 1-419 p.

Boxshall, G.A., Halsey, S.H., 2004 b. An introduction to Copepod Diversity. Part II, The Ray Society Instituted. London, 420-966 p.

Bradford-Grieve, J. M., 1999. The Marine Fauna of New Zealand: Pelagic Calanoid Copepoda, National Institute of Water and Atmospheric Research (NIWA),268 p..

Brodsk11, K. A., 1950. Calanoida of the Far Eastern Seas and Polar Basin of the USSR. Keys to the Fauna of the USSR. Zoologi. Instutue of the Academy of Sciences of the USSR, 35, 1-440 p.

Chicharo, M. A., Chicharo, L. M., Galvao, H., Barbosa, A., Marques, M. H., Andrade, J. P., Esteves, E., Miguel, C., Gouveia, I., 2001. Status of tehe Guadiana Estuary (south Portugal) during 1996-1998: An Ecohydrological approach Aquatic Ecosystem Health \& Management 4(1), $73-89$ p.

Crump, B.C., Baross, J.A., 1996. Particle-attached bacteria and heterotrophic plankton associated with the Columbia River estuarine turbidity maxima.Marine Ecology Progress Series.Vol. 138: 265-213.1

Dönmez, A., 1998. İskenderun Körfezi'nin Botaş (Yumurtalık) ve Arsuz (İskenderun) Aras1 Kiyı Alanında Copepoda ve Cladocera (Crustacea) Gruplarına Ait Zooplanktonik Organizmaların Dikey Dağılımı ve Mevsimsel Değişimi. Çukurova Üniversitesi Fen Bilimleri Enstitüsü Su Ürünleri Anabilim Dalı Doktora Tezi, Adana.

Dussart, B.H., Defaye, D.,2001. İntroduction to the Copepoda. 2th editition, Backhuys Publisher, Leiden.336 p.

Edmondson, W. T.,1959-a. Rotifera: Freshwater Biology. 2nd JohnWiley\&Sons Inc., 420494 pp., New York. 
Edmondson, W. T., 1959-b. Cladocera: Freshwater Biology. 2nd JohnWiley\&Sons Inc., 587-656 pp., New York.

Edmondson, W. T., 1959-c. Free-Living Copepoda: Freshwater Biology. 2nd JohnWiley\&Sons Inc., 735-861 pp., New York.

Einsle, V., 1996. Copepoda: Cyclopoida Genera Cyclops, Megacyclops, Acanthacyclops. Coor. Edit: Dumont, H. J., Guides to the Identification of the Microinvertebrates of the Continental Waters of the World. SPB Academic Publishing bv.

Elster, H.J., Ohle, W., 1974. Plankton Rotifer Biology and Taxonomy. Chapter 'Die Rotatorien' Stuttgart.

Erdoğan, Ö. 2011. İki Nehirağzı Bölgesinde (Köprüçay ve Manavgat Nehirleri) Zooplanktonun Taksonomik ve Ekolojik Yönden Araştırılması. T. C. Süleyman Demirel Üniversitesi Fen Bilimleri Enstitüsü, Su Ürünleri Temel Bilimler Anabilim Dalı Doktora Tezi Eğirdir/ISPARTA.

Frost, B., Fleminger, A. 1968. A revision of the genus Clausocalanus (Copepoda: Calanopoda) with remarks on distributional patterns in diagnostic characters. Bulletin of the Scripps Institution of Oceanography 12, 1-235 p.

Grice, G.D., 1962. Calanoid copepods from Equatorial waters of the Pacific Ocean.Fishery Bulletin, 61:1072, 171-246 p.

Harris,R.P., Wiebe, P.H., Lenz, J., Skjoldal, H.R., Huntley, M., 2000. Zooplankton Methodology Manual. Academic Press.683 p.

Holst, H., Zimmermann, H., Kausch, H., Koste, W., 1998. Temporal and spatial dynamics of planktonic Rotifers in the Elbe Estuary during Spring. Estuarine, Coastal and Shelf Science,47, 261-273 p.

Isinibilir, M., Kideys, A. E., Tarkan, A.N., Yilmaz, I.N. (2008). Annual cycle of zooplankton abundance and species composition in Izmit Bay (the northeastern Marmara Sea). Estuaries, Coastal and Shelf Science, 78 (2008), 739-747 pp.

Kasturirangan, L. R., 1963. A key for the Identification of the more common planktonic Copepoda of Indian Coastal Waters. Counsil of Scientific- Industrial Research, New Delhi, 2,2-87 p .

Khalil M.T., EI-Rahman., N.S.A., 1997. Abundance and diversity of surface zooplankton in the Gulf of Aqaba, Red Sea, Egypt. Journal of Plankton Research 9 (7): 927936.

Kocataş, A., 2006. Ekoloji ve Çevre Biyolojisi.Ege Üniversitesi Su Ürünleri Fakültesi Yayınlan No:51 Ders Kitabi Dizini No:20 Bornova/IZMIR.

Koste, W., 1978-a Rotatoria. Überordnung Monogononta. Die Rädertiere Mitteleuropas, I. Textband, p. 670, II. Tafelband, 670 p., Berlin.

Koste, W., 1978-b. Rotatoria. Überordnung Die Rädertiere Mitteleuropas II.Tafelband, 235 p., Berlin.

Küçük, F., 1997. Antalya Körfezine Dökülen Akarsuların Balık Faunası ve Bazı Ekolojik Parametreleri Üzerine Bir Araştırma. T. C. Süleyman Demirel Üniversitesi Fen Bilimleri Enstitüsü, Su Ürünleri Mühendisliği Anabilim Dalı Doktora Tezi Eğirdir/ISPARTA.

Mazzocchi, M.G., Zagami, G., Ianora, A., Guglielmo, L., Crescenti, N., Hure, J., 1995. Atlas of Marine Zooplankton, Straits of Magellan. Springer-Verlag Berlin. 652p.

Miyashıta, L.K., Junır, M.M., Lopes, R.M., 2009. Estuarine and oceanic influences on Copepod abundance and production of a subtropical coastal area. Journal of Plankton Research 31 (8): 815-826 p. 
Naumenko, E.N., 2009. Zooplankton in different types of estuaries (using Curonian and Vistula Estuaries as an Example). Inland Water Biology, 2009, 2 (1):72-81 p.

Newel, G.E., Newel, R.C., 1977. Marine Plankton, A Practical Guide. Hutchinson Pisces Conservation Ltd, London.244 p.

Özel, T., 1992. Planktonoloji. Ege Üniversitesi Fen Fakültesi Yayınları No: 145. Bornova/İzmir.

Özel,İ., 2003. Planktonoloji II. Denizel Zooplankton. Ege Üniversitesi Su Ürünleri Fakültesi Yayınları No:49. Bornova-İzmir.

Palomares, R., Suarez-Morales, E., Hernandez-Truj1llo, S., 1998. Catalogo de los Copepodos (Crustacea) Pelagicos del Pacifico Mexicano, Impreso y Hecho en Mexico, $352 \mathrm{p}$.

Perry, R., 2003. A Guide to the Marine Plankton of Southern California, 3 rd. edition. Ucla Ocean Globe, 1-23 p.

Pontin, R.M., 1978. A Key to British Frehswater Planktonic Rotifera. Frehswater Association Scient. Publ. No:38, 178 p., UK.

Puelles, M.L.F., Valencia, J., Jansa, J., Morillas, A., 2004. Hydrographical characteristics and zooplankton distribution in the Mallorca channel (Western Mediterranean): spring 2001. ICES Journal of Marine Science, 61: 654-666 p.

Rose, M., 1933. Copepodes Pelagiques. Fauna du France, 26,: 1-374 p.

Rutner- Kolisko, A., 1974. Plankton Rotifers: Biology and Taxonomy. Vol. XXVI, Part 1, E. Schweizerbart'sche Verlagsbuchhandlung, 146 p., Stuttgart.

Sautour, B., Artigas, F., Herbland, A., Laborde, P.1996. Zooplankton grazing impact in the plume of dilution of the Gironde estuary (France) prior to the spring bloom. Journal of Plankton Research,18 (6): 835-853.

Sever, M.T., Mavili.S., 2002. İzmir Körfezi (Ege Denizi)'nde Corycaeidae (Copepoda) Familyasi Türlerinin Dağılımı Üzerine İlk Gözlemler. Ege Üniversitesi Su Ürünleri Dergisi Cilt/Volume 19, Say1/Issue (1-2): 227-232 p.

Smirnov, N, N., 1996. Cladocera: The Chydorinae and Sayciinae (Chydoridae) of the World. Coor. Edit: Dumont, H. J., Guides to the Identification of the Microinvertebrates of the Continental Waters of the World. SPB Ac. Publ. bv.

Sterza, J.M., Fernandez L.L., 2006. Zooplankton community of the Vitória Bay estuarine system (Southeastern Brazil). Characterization during a three-year study. Braz. Journal Oceanogr. $54: 2-3$

Tregouboff, G., Rose, M., 1957. Manuel De Planctonologie Mediterraneenne. Cent. Nati. Dela Res. Scient. 15, Anotole-France, 107-123 p.

Vieira,L., Azeiteiro U., Re, p., Pastorinho, R., 2003. Marques ,J.C., Morgado, F., Zooplankton distribution in a temperate estuary (Mondego estuary southern arm:Western Portugal). Acta Oecologica 24: 163-173 p.

Zununi, T., 2006.Clausocalanus and Paracalanus identification and species distrubution in the Mediterranean Sea. Crustacean Zooplankton Taxonomic Workshop, Section 6. 